\title{
O DESENCANTO DA POLÍTICA E O TOTALITARISMO EM HANNAH ARENDT: PERCEPÇÕES DO GOLPE DE 1964
}

\author{
Ana Paula de Castro Sousa ${ }^{1}$ \\ Jeovandir Campos do Prado ${ }^{2}$ \\ Antonio Bosco de Lima $^{3}$
}

\begin{abstract}
RESUMO
Estabelecer uma relação entre o golpe militar e o período da ditadura que vigorou no Brasil entre 1964 e 1984 e as tese de Arendt é o objeto central desde trabalho, destacando-se o poder político, as ideias de totalitarismo, de individualismo e de liberdade. Condensa-se neste trabalho o postulado que o golpe de 1964 caminhou paralelamente com a perspectiva de individualização, de uma sociedade para o mercado, afastada do social-coletivismo, agregada a um modelo de liberdade vigiada, contrária à essencialidade de liberdade presente no pensamento de Arendt.

Palavras-chave: Poder; política; golpe de 1964; individualismo; liberdade.
\end{abstract}

\section{THE POLITICS' DISENCHANTMENT AND THE TOTALITARIANISM AS SEEN BY HANNAH ARENDT: PERCEPTIONS OF 1964 COUP IN BRAZIL}

\begin{abstract}
This study seeks to establish a relationship between the military coup and following military rule which took place in Brazil between 1964 and 1984 and the theses of Hannah Arendt. It does so by problematizing the political power and ideas of totalitarianism, individualism and freedom based on the postulate that the 1964 coup unfolded alongside the prospect of an individualization - from society to the market - that is away from social collectivism and aggregated to a model of freedom which is under surveillance, i. e., which goes against the essence of Arendt's idea of freedom.
\end{abstract}

Keywords: power; politics; 1964 coup; individualism; freedom.

\section{Reflexão de um passado ainda presente}

\begin{abstract}
A história dos últimos 50 anos da Democracia no Brasil tem algo a ver com a trajetória de um cometa: de 1930 a 45 ela foi gravitar em outras órbitas. Reapareceu em janeiro de 46 e permaneceu por 18 anos sobre nossas cabeças. Em 64 novamente saiu de órbita (até 74 era impossível vê-la, mesmo com os mais possantes telescópios). Retornou agora (15 de março de 1985), sexta-feira, mas ainda não dá para observá-la a olho nu só através de boletins. Seu ciclo, percebe-se, sofre uma variação que vai de 15 a 21 anos. O astrônomo-chefe do Observatório Nacional tranquilizou a população: "Um novo eclipse político só deverá ocorrer nos primeiros anos do próximo século". (NOVAES, 1986, P. 19).
\end{abstract}


Meio século depois daquele 31 de março no ano de 1964, o Brasil tem a oportunidade para a reflexão e aprofundamento dos acontecimentos históricos que levaram a um período de restrição política. A ditadura e, com ela, a coerção, a censura, a limitação dos espaços políticos, o silenciamento das vozes e o apagamento das memórias. Lembranças de um passado que teimam em desconfiar da realidade presente acampada em frágil tenda democrática.

Trinta anos depois, se consideramos a luta pelas Diretas Já como marco pela democratização do país, temos a oportunidade e a obrigatoriedade de fazermos um balanço sobre a redemocratização do país. Vários eventos estão fazendo tal debate neste ano de 2014, coordenados por variadas instituições/organizações, sejam estudantis, politico partidárias, acadêmicas, sindicais. Não importa a corrente, tampouco a origem das organizações, importa que o povo brasileiro tenha na memória que sofremos um estado restritivo, autoritário, de terror, o qual precisamos compreender para que nunca mais (referenciando o livro organizado pelo Cardeal Arns) ocorram sequelas como esta, a qual, a nosso ver causou um estrago/atraso sem dimensão e sem precedentes ao povo brasileiro.

$\mathrm{O}$ desafio para este texto consiste em problematizar temas diretamente imbricados à política, à ditadura e ao totalitarismo que resultaram, no período descrito, na redução do espaço de atuação da atividade política. A familiaridade com os temas fez com que elegêssemos trabalhar com parte da vasta bibliografia de Hannah Arendt que indica um entendimento distinto sobre a política na modernidade. Por outro lado, a autora também se esteia, em nosso entendimento, na superfície aparente dos fenômenos quando oferece na sua teoria política alternativas para uma realidade totalitária.

Em toda a obra, Entre o passado e o futuro, Hannah Arendt (1997) não desenvolveu de forma temática explícita a ideia de ruptura, mas constata-se que o conceito tangencia seus escritos com possibilidade para o entendimento do sentido do fenômeno político presente com vistas para o futuro. A autora priorizou o totalitarismo como evento para uma melhor compreensão desse conceito. O presente estudo, também foi elaborado a partir de outras leituras arendtianas: Da revolução (1988), Origens do Totalitarismo (1989), O que é Política? (1999) e que serviram de arcabouço para interpretar momentos de "destruição" no espaço político tão interessante aos regimes totalitários. Toda essa reflexão tem como objetivo transitar por parte das afirmações de Arendt que perpassam seu tempo e se (o)põem pertinentes ao pensar, os "50 anos do golpe e do regime civil militar" no Brasil, através do resgate e interpretação do conceito de política e totalitarismo.

As marcas produzidas nesse período ainda estão salientes quando pensamos que o sinônimo de ditadura é a coerção e a limitação do espaço de atuação política. Da crença na centralidade e materialidade do poder. Na limitação da liberdade e da ação política, consideradas nos moldes arendtianos, como ausência de pluralismo, enfraquecimento e desmobilização da sociedade civil em torno das questões políticas.

Retumba as palavras de Gabeira (1982, p. 24), reforçando a argumentação anterior: "De que adiantavam as armas se os principais partidos políticos não tinham tensionado suas forças para resistir? E de que adiantava os partidos fazerem isto, se a sociedade no seu conjunto não estava convencida da importância de resistir?"

Mas também, quais são as alternativas de mobilização num sistema de repressão política? O Projeto Brasil: nunca mais revela uma história oculta escrita por aqueles inconformados com a realidade vivida e que, de certa forma, contribuíram para o desenvolvimento de uma consciência "acerca de se construir sistemas políticos que efetivamente erijam a pessoa humana como valor inviolável" $(1985$, p. 8). As privações e torturas promovidas pelo regime "totalitário" no período político brasileiro ainda ecoam com muita virulência nos porões da realidade cotidiana. 
Os achados e perdidos documentais da época da ditadura civil/militar deixam transparecer os ranços ideológicos dominantes ainda vivos em nossos dias, da fé propagandeada pelo estado autoritário presente na hegemonia editorial dos principais veículos de comunicação ao dar voz a uma minoria. As "Marchas das Famílias com Deus pela Liberdade" expressam bem letalidade das armas empunhadas pelos setores dominantes da sociedade. Que, naquele tempo, tratou de dar um ar de legalidade ao Golpe ao referir-se a ele como "revolução".

É tão jocoso e inverossímil que, além de reportarmo-nos a literatura da ciência social, iremos, também abraçar o grande Novaes, ao fazer uma brincadeira em seu livro Democracia à vista (1981, p. 13). Escreve:

Fico estarrecido com a cara-de-pau com que homens que defendiam a caça à bruxas, a Censura, o AI-5, o senador biônico, a Lei Falcão desfilam por aí, lépidos e fagueiros, dizendo-se democratas desde criancinhas.

O Governo está querendo driblar a História e com isso vai entortando cabeças. Suas declarações a favor da democracia são feitas com tamanho fervor que chego a pensar que durante os 15 anos de ditadura e repressão, quem estava no Poder era a Oposição.

É interessante observar que ideologicamente o termo "revolução" carrega consigo um teor transformador da realidade social (reformas, desenvolvimento, progresso e dinamismo), como destaca Miranda (2010), reformas de "verdade". Ao mesmo modo, democracia pode ser adulterada, traída, estuprada, violentada, dilapidada, torturada. Mas, ... para o próprio bem dela.

Arendt (1988), em Da revolução, faz um "esforço", ao descrever os processos revolucionários e para isso toma como exemplo as revoluções americana e francesa. Descreve que os dois modelos revolucionários foram responsáveis por introduzir mudanças significativas para as respectivas realidades e, em comum, o uso da violência e o caráter de novidade. No entanto, nem a novidade e a violência, "nenhuma delas parecia dar origem a algo novo" (p. 17), apenas uma mudança de estágio num curso pré-determinado. Ressalvadas as proposições arendtianas sobre os processos revolucionários e sua preferência ${ }^{6}$, no caso da "Revolução" ou Golpe de 64, do mesmo modo não significou uma mudança de modelo e de uma nova sociabilidade, apenas um abalo sísmico no sistema político que acusava o deslocamento de seus atores principais, como afirma Francisco de Oliveira (2006).

É nesse teatro que se desenrola a trama desse artigo e cujo cenário, "revolucionário" ou "golpista", amarelado pelo tempo parece destoar da realidade Touch Screen mas, só aparenta. As visões de mundo predominantes espraiadas nos diversos campos: de comunicação, educacional, político, religioso, ... insistem, como período precedente, com poucas exceções, em desqualificar ações políticas de natureza mais violenta preferindo o consenso. Àquele mesmo bastante difundido pelo ordenamento liberal.

Aliás, no próprio seio das manifestações contrarias ao golpe e a ditadura, abalou-se a disputa pela transição pacífica, ordeira e cultural/educacional e a que transgredia o modelo de transição política, por uma luta armada. Gabeira (1982, p.93, grifos no original) em seu livro de memórias O que é isso companheiro? registra a disputa "Quando as 100 mil pessoas desfilavam pela Avenida Rio Branco, algumas gritavam 'só o povo armado derruba a ditadura'; outras gritavam 'só o povo organizado derruba a ditadura'. A escolha 
entre um e outro adjetivo era objeto de uma surda luta interna das correntes políticas que disputavam a hegemonia do movimento."

Sobre Marx, Arendt (1988) entende que ao deslocar o conceito de história embriagada em vinhos da liberdade e submetê-la ao "império absoluto da necessidade", aniquilou as qualidades imanentes ao espaço político. Para a autora, a capacidade política ficou comprometida pelo fato de a pobreza e a liberdade serem incongruentes. Arendt, insiste em negar as análises marxianas ao contrapor ou negligenciar a exploração e a origem da propriedade privada. Ao recusar os construtos históricos de Marx e elevando, no âmbito da política, a dimensão privada da vida humana sobre a dimensão social a autora se "avizinha" perigosamente das bases ontológicas liberais.

É pertinente recorrer à literatura ficcional, pois seu tom lúdico pode esmerar de forma didática outras compreensões sobre o discurso bem elaborado filosoficamente (e também fisiologicamente). Novaes (1985, p. 29), novamente, registrando de forma rudimentar um diálogo entre dois personagens de A história de Cândido Urbano Urubu, deixa de maneira explicita a existência de classes sociais distintas ${ }^{7}$

- Classe? Que é classe?

- É uma forma de distinguir os homens - explicou Noé, procurando ser claro - de separá-los em categorias sociais.

- Mas os homens não são todos iguais? Não formam uma família, como os outros animais?

Noé respondeu, movendo apenas o indicador, como um limpador de parabrisas.

- E o que distingue uma classe da outra? - tornou Cândido. - A altura? O peso? A cor?

O velho Noé espantou as moscas e observou que, em certos países, era possível saber, pela cor, a que classe os homens pertenciam; "normalmente, os pretos pertencem à classe baixa".

Discutir, hoje, a questão de classe, de realidade, de mundo prático, de transformação, de emancipação, da relação público x privado, pode parecer, e às vezes o é, uma questão de escolástica, mas, para nós, a tese que nos guia neste artigo, condiz com os princípios de uma sociedade em disputa, de projetos em disputa, da contradição instaurada em nossas vidas, em nosso Estado, em nossa sociedade.

\section{Do conceito de política para Hannah Arendt}

Há três dimensões que caracterizam conceito de política para Arendt. A primeira dimensão é a ruptura como evento, isto é, algo absolutamente novo, inédito que surge e rompe com a estrutura do pensamento. Exemplo: o ineditismo político do totalitarismo. A segunda dimensão é a mútua negação entre o fato e o pensamento, pois o fato na história nega toda a tradição intelectual e como consequência desta negação surge a terceira dimensão. Na terceira dimensão faz necessária a reposição das relações entre o evento e o passado, ou seja, há de se pensar sob uma nova concepção histórica, o fato e o passado.

Arendt (1999) revisita o passado no mundo grego, no moderno e no contemporâneo para interpretar como se definiram as capacidades humanas através da história do pensamento. Na poesia e na historiografia grega há uma intensa preocupação com a grandeza dos feitos e palavras dos homens. Esta preocupação está intimamente ligada com os conceitos de natureza e de história. A natureza é imortal através dos ciclos repetitivos da vida, ela se mantém para sempre. E os homens, enquanto indivíduos, precisam da 
imortalidade para se perpetuarem na história. Na Antiguidade, percebe-se o conceito de ação pelos grandes feitos que se revelam em si e por si mesmos sendo perpetuados na história através da palavra escrita. A ação não tem em mente o produto final, age, inicia novas cadeias de acontecimentos e assim sucessivamente. Há duas possibilidades de objetividade grega: a imparcialidade e a compreensão. A imparcialidade está presente ao descrever os feitos dos troianos e dos aqueus com fins em si mesmos. A compreensão ocorre no sentido de ver um problema sob vários aspectos focalizando o bem comum.

No mundo moderno, o conceito de natureza está também ligado com o conceito de história. O método experimental aplicado nas ciências naturais era considerado de forma imprópria na história, segundo Arendt (1997). Os físicos, no desenvolvimento de seus experimentos eram altamente objetivos, isto é, não interferiam nos fatos, porém, o impasse ocorre na subjetividade dos fatos humanos estudados pelos historiadores como tema de discussão, a objetividade na ciência histórica. Parece que a imparcialidade e a compreensão dos gregos não estão presentes na época moderna. A grandeza em si mesma dos eventos que aspirava a imortalidade no período grego não sobrevive na era cristã.

O Cristianismo, conforme Arendt, traz na concepção que nem o mundo e nem o ciclo de vida são imortais, apenas o indivíduo é eterno. A subjetividade e a sacralidade da vida fundamentam a alienação do homem chegando a destruir o que ele fez e o que ele não fez. Em meio à discussão de objetividade e subjetividade no conceito de história surge Vico, dizendo, que o homem é capaz de conhecer aquilo que pelo menos ele fez, consequentemente, é possível compreender a história através do pensamento no mundo social. Assim, a história torna-se um processo feito pelos homens. As ciências naturais e os feitos humanos, com seus experimentos, passam a interferir na natureza assegurando um desenvolvimento cujo progresso foi muito amplo.

O cientista não apenas deixou para trás de si o leigo com sua compreensão limitada; ele deixou para trás uma parte de si mesmo e de seu próprio poder de compreensão, que é ainda compreensão humana, ao ir trabalhar no laboratório e começar a comunicar-se em linguagem matemática (ARENDT, 1997, p. 330).

Para a autora, a fabricação na história ocorre devido a estes homens compreenderem o seu agir na natureza. $\mathrm{O}$ conceito de fabricação consiste em um início definido e um fim possível. Na época contemporânea desaparece o outro como fim em si mesmo. Não há como medir o efeito da ação. Os contemporâneos possuem um conceito de ação diferente dos gregos, cuja característica se baseia no tudo é possível, já que o homem age na natureza e na história. E com o desenvolvimento da tecnologia passa inclusive a "criar" a natureza e interferir nos processos naturais. Essa ação de "criar" a natureza é perigosa e suas reações são impredizíveis. Os recursos tecnológicos são importantes, mas há que se pautar na concepção de onde os cientistas partem, na maneira como eles questionam a realidade no momento em que vivem. Este método depende de como o cientista elabora a questão. Podemos citar como exemplo, ocorrido no século passado, a explosão da bomba atômica na cidade de Hiroshima. Os efeitos deste ato são visíveis até hoje na natureza e na estrutura genética da população local. No entanto, não há como atender as vítimas que perderam sua individualidade, pois, estas vítimas não têm como recorrerem à justiça para julgar o passado. As regras não possuem aplicação, nem são coerentes com a concepção histórica do passado.

Com efeito, Hannah Arendt, com seu conceito de ruptura, sutilmente nos alerta, que as questões são direcionadas à natureza e as consequências estão voltadas para os homens e 
que nem sempre é possível prevê-las. As aplicações da ciência, as decisões políticas não deveriam ser decididas pelos cientistas ou políticos, mas por uma comunidade mais ampla.

Por outro lado, Hannah Arendt observa nos regimes totalitários a "destruição" do espaço político, uma vez que a liberdade desses homens foi de certo modo anulada. Para ela: "a política baseia-se na pluralidade dos homens. Deus criou o homem, os homens são um produto humano mundano e produto da natureza" (ARENDT, 1999, p. 21). A política baseia-se na pluralidade dos homens e trata da convivência entre diferentes, isto é, a política organiza parâmetros coletivos para a convivência dos homens em diferentes espaços e tempos. Mas, ela não faz parte da essência humana, uma vez que a autora considera o homem um ser a-político. "A política surge no intra-espaço [espaço entre homens] e se estabelece como relação" (ARENDT, 1999, p. 23). Considerando a rebelião dos homens uns contra os outros, a política vai trazer um sentido para a vida humana. "A política organiza, de antemão, as diversidades absolutas de acordo com uma igualdade relativa e em contrapartida às diferenças relativas" (ARENDT, 1999, p. 24).

Disso decorre, a liberdade do homem se expressar. O espaço político é entendido como um mundo plural que comporta homens distintos e comum a todos os homens. Hannah Arendt considera o mundo político como o palco da ação, da troca de opiniões onde os seres humanos mostram suas diferenças e singularidades. Essa possibilidade do ser humano poder expressar nesse mundo estimula o seu interesse pela política. O espaço político se baseia na liberdade das experiências humanas, transformando essa oportunidade num impulso para a participação política, sem, contudo, ferir as singularidades.

Ora, esta é uma manifestação que prima pelo individualismo, pois, bem sabemos que o coletivo respeita as singularidades e a subjetividade, porém está acima delas, movese no sentido destas se adequarem ao coletivismo, ao contrário o individualismo agregado à individualidade tenta segregar o coletivismo, tornando-o refém e reduzindo o coletivo a uma soma de ações distintas de homens distintos, com vontades distintas. Seria dizer: todo poder ao indivíduo. Toda liberdade ao individuo, que está, claro, sujeito a uma outra liberdade. Senão vejamos, novamente, por intermédio de Novaes (1985, p. 70): "Numa sociedade de livre iniciativa, a primeira iniciativa que você deve tomar, nem que seja tomar emprestado, é conseguir dinheiro, sem o que você não será ninguém”.

A discussão política é realizada no intra-espaço (no espaço entre os homens) configurando a liberdade. Sem a liberdade é impossível a ação política. Haja vista, a questão das ditaduras onde não há espaço para a discussão. Arendt (1997, p. 191), argumenta, "para as questões da Política, o problema da liberdade é crucial", remete a política à liberdade pelo fato de que a liberdade e a política correspondem à participação ativa dos cidadãos em sua pluralidade e, comum a todos, a ocupação do espaço público. Disso se deriva, que a convivência livre entre os diferentes expressa o sentido da política e, sem a liberdade, o espaço político torna-se inviável.

A raison d'être da política é a liberdade, e seu domínio de experiência é a ação. A liberdade que admitimos como instaurada em toda a teoria política e que mesmo os que louvam a tirania precisam levar em conta é o próprio oposto da "liberdade interior", o espaço íntimo no qual os homens podem fugir à coerção externa e sentir-se livres. Esse sentir interior permanece sem manifestações externas e é portanto, por definição, sem significação política (ARENDT. 1997, p. 192).

$\mathrm{Na}$ Antiguidade, se identificavam liberdade e política sendo uma a razão de ser da outra. Na modernidade, assiste-se uma separação entre elas. E, na contemporaneidade, a dimensão política está enfraquecida e desacreditada em consequência da visão negativa 
que se tem de política e políticos. Os preconceitos nos afastam da ação política, porém isso não é irreversível. O distanciamento da política não surgiu por acaso e de maneira repentina, mas no decorrer da história ele veio se construindo, gestado na esfera do público e não do privado. Em consequência desses fatos, especialmente em momentos de autoritarismo, a maioria dos indivíduos negligenciam a dimensão política e não conseguem admitir a política como espaço de liberdade. Diante de todas essas constatações, Arendt (1999) reconhece a falta de evidência da identidade entre a política e liberdade, e ela se pergunta se a participação na esfera pública do mundo tem significado para os seres humanos. E mais, Hannah Arendt questiona sobre a possibilidade de ainda assim atribuir sentido a política, se continua legítimo fazer política ou é uma retórica apenas.

A despeito de fazer estes questionamentos, a filósofa alemã considera que os acontecimentos desastrosos, no século XX, ocorreram em consequência do afastamento das pessoas na esfera pública não exercendo uma ação contrária a eles. Dessa maneira, abriu-se a possibilidade para o surgimento do Totalitarismo, percebido como uma nova forma de governo ou uma nova categoria política, que não visava apenas reprimir ou limitar a liberdade dos cidadãos, mas sim destruí-la.

Este distanciamento do homem comum em relação á complexa sociedade também está presente no período por nos analisado neste trabalho. Gabeira ao relatar sua experiência enquanto guerrilheiro urbano, comenta uma das ações:

Na missa de Natal de 68, planejamos uma grande panfletagem do Resistência. Era um número especial do AI-5, com um editorial explicando sumariamente suas causas. Juntei-me com um grupo de secundaristas e fomos para as portas das igrejas. Grande parte das pessoas não conhecia o jornal e o jogava fora, mal tomando conhecimento do que se tratava. Foi um Natal de cão, em 1968. Havia muita gente presa, um corre-corre geral e os indícios de resistência eram quase nulos. haviam dado um golpe (Edição do Ato Institucional número 5) num momento exato, quando o nível de mobilização era o mais baixo possível. E haviam dado o golpe no fim de não, aproveitando a confusão das festas, compras de Natal e férias. (p. 120, grifo no original).

Os homens dos governos totalitários no período da II Guerra Mundial, aniquilaram a liberdade humana ao transformarem o intra-espaço da política ou da liberdade em lugar de violência, coação e de morte para estabelecer um domínio total sobre as pessoas. $\mathrm{O}$ domínio foi mantido pela força ideológica e pelo terror extinguindo com isso o verdadeiro sentido da política, que é a livre participação dos cidadãos na esfera pública.

A ação do terror aniquila a ação política dos homens uma vez que ela cria o medo e o medo impede a ação. Igualmente, isola os homens uns dos outros, destruindo a pluralidade humana. A autoridade para ser exercida necessita sempre de obediência, por isso ela é confundida ao longo da história como alguma forma de poder ou de violência. Assim, é importante reconhecer a dimensão do que está sendo posto em discussão e aceitar, dentro de um consenso que decorre a obediência e, consequentemente, a autoridade. Do mesmo modo, que a autoridade prescinde da coerção, da persuasão e da violência, ela pressupõe a existência de uma hierarquia entre os que estabelecem o consenso. A expressão: "manda quem pode, obedece quem tem juízo" possui outra conotação quando explicada por argumentos arendtiano.

A relação autoritária entre o que manda e o que obedece não se assenta nem na razão comum nem no poder do que manda; o que eles possuem 
em comum é a própria hierarquia, cujo direito e legitimidade ambos reconhecem e na qual ambos têm seu lugar estável predeterminado (ARENDT, 1997, p. 129).

A concepção de política trazida por Arendt (1997) pretende conciliar liberdade e a política, mas não a política nos moldes que conhecemos em que estes dois polos estão distanciados. Arendt se apega à política enquanto conceito filosófico e que a modernidade foi responsável por retirar a sua capacidade de ação. Então, qual seria o significado da política e a possibilidade da liberdade humana em nossos dias? Considerando-se a quase ausência da ação política da sociedade contemporânea, portanto, o afastamento dos seres humanos na participação da esfera pública do mundo, como pensar a política enquanto espaço de liberdade e ação humanos nos moldes arendtianos?

Arendt (1997) justifica que a política perdeu seu espaço de ação a partir do momento em que passou a se preocupar com as necessidades humanas e se afastou do seu sentido filosófico, ou seja, da finalidade da política em si mesma. O século XX, traz consigo a dominação e a massificação de grande parte da população que não se percebe responsável pelo mundo comum, atribuindo a responsabilidade política aos políticos profissionais. Esse vazio do pensamento é típico do homem produzido pela modernidade na percepção dessa autora. Nesse contexto, a sociedade, muitas vezes, não tem a exata consciência do que dignifica o homem é a participação na esfera política.

Dessa perspectiva, continuamos inscientes do verdadeiro conteúdo da vida política - da recompensadora alegria que surge de estar na companhia de nossos semelhantes, de agir conjuntamente e aparecer em público; de nos inserirmos no mundo pela palavra e pelas ações, adquirindo e sustentando assim nossa identidade pessoal e iniciando algo inteiramente novo. (ARENDT, 1997, p. 325).

Como falar da política como espaço da liberdade em uma sociedade que está mais preocupada com a luta pela própria sobrevivência ou que valoriza mais o consumo e a produção? Ou ainda, que não sente garantido esse espaço de liberdade e ação, e também, não se sente parte desse mundo comum? A busca por respostas a estas inquietações passa justamente, no pensamento de Hannah Arendt, na inflexão das rupturas do autoritarismo na contemporaneidade. Na condenação da apatia desse homem social que se exime da responsabilidade coletiva em detrimento da culpabilização quase que individual. Para a autora, que não raro se deixa levar pela a influência do affaire heideggeriano, está o interesse na distinção entre o puro pensar e o não pensar. A alienação em relação a sua realidade e a si mesmo.

Hannah Arendt considera inevitável, para salvaguardar a política do desastre, a renovação do espaço político. Ela considera possível porque o homem detém a capacidade de agir no mundo constantemente, reconhece sua liberdade de ser, de iniciar uma nova possibilidade para sua existência e de reiniciar-se a si mesmo: fazer "milagre". A capacidade dos homens para a ação não terá fim enquanto a política, espaço da comunicação entre os homens, estiver viva e a liberdade se fizer presente no intra-espaço. No entanto, essa tarefa se mostra cada vez mais complexa, diante da apatia e do retraimento do homem moderno no que concerne a ocupação desses espaços, frente aos diferentes tipos de autoritarismo que se fazem presentes em nossos dias. 


\section{O milagre arendtiano}

No momento em que se rememora esse nosso passado inglório, a "antirrevolução" de 1964, que instituiu uma ditadura no Brasil com duração de 21 anos e cujo resultado foi obstrução deste espaço instaurando o medo e a repressão, as percepções arendtianas tendem a cair no vazio. $O$ afastamento do homem da esfera de decisões não deve ser imputado somente a sua limitada capacidade de interação com a realidade nas suas múltiplas expressões, mas também relacionado à materialidade e organicidade de um Estado historicamente situado.

A herança existencialista no pensamento de Hannah Arendt insiste ao dizer que o vazio político tem relação com o deslocamento da ontologia (atividade vital) na modernidade e com isso, submeteu a política às necessidades da história e suas exigências naturais e sociais do homem. Ao fazer isso, retirou-se o teor plural da política em si mesma, que é exterior ao homem e as suas necessidades, e também sua imprevisibilidade. Em Origens do totalitarismo, Arendt (1989), diz que o desinteresse pela sociedade de massa (composta de indivíduos atomizados) se comportam apenas como peças de uma engrenagem do processo de produção e consumo e que se desinteressam e se desresponsabilizam pela política. Segundo a autora é dessa previsibilidade da condição humana que os regimes totalitários se aproveitam eliminando o espaço da política.

Entretanto, Kosik (1976, p. 23) faz um alerta que nos ajudam a problematizar as questões trazidas por Hannah Arendt, expressado da seguinte maneira: "o homem vive em muitos mundos, mas cada mundo tem uma chave diferente, e o homem não pode passar de um mundo para outro sem a chave respectiva, isto é, sem mudar a intencionalidade e o correspondente modo de apropriação da realidade". A chave utilizada por Arendt na sua investigação, a essência do fenômeno da política e do totalitarismo, deixa escapar o essencial.

Ela deseja chegar à realidade não através de um complicado processo regressivo-progressivo (no curso do qual e graças a cuja atividade a realidade se cinde em essência e inessencial, ao mesmo tempo em que se justifica esta cisão), porém através de um salto que a coloca acima das aparências fenomênicas; mesmo sem examinar tais aparências, este gênero de investigação já sabe o que é a essência e como alcançá-la (KOSIK, 1976, p. 57).

Recorrer às percepções arendtianas como instrumento de reflexão parece desafiador quando tentamos conciliar espaço de atuação política, pluralidade e liberdade dentro de um regime de repressão política. Quando ignorado a economia no seu aspecto determinante da ordem social e política. Dos incontáveis "condenados sem crime" que, insistindo em atuar nesses minados espaços, foram privados de suas liberdades e de suas vidas. A solução "milagrosa" que propõe Arendt para a ampliação do espaço entre os homens em um regime político ou Estado essencialmente totalitário sugere o nascimento de um novo homem que não esteja preso às concepções da modernidade. Fica implícito nos arranjos arendtianos a descrença nos fundamentos que sustentam a democracia estabelecida. Nesse aspecto, ainda que concordemos com essa descrença, as soluções não podem ser idealizantes/idealizadoras. 


\section{Algumas considerações}

Ao transitarmos pelo pensamento de Hannah Arendt e seus conceitos de política e totalitarismo e, ao mesmo tempo, negamos a "história da necessidade", com palavras mais enfáticas, negamos: a desigualdade, a propriedade privada e renda, o poder, o uso da força, a privação da liberdade intelectual e física, as torturas, os privilégios, ... e tantos outros atributos que se fizeram presentes no Estado golpista. Os 50 anos do Golpe civil/militar traz na sua essência a relação desigual de forças desse Estado preocupado com o ordenamento capitalista, das ameaças comunistas que só os golpistas acreditavam existir e do medo de que as classes trabalhadoras pudessem obter algum progresso.

A herança deixada por esse período, no campo das aspirações políticas, foi de um "reaprender" a caminhar rumo aos processos democráticos. O hiato temporal fez reaparecer um afã democrático que infelizmente não se consubstanciou como desejávamos. A redemocratização (o tempo de experiência perdido), tão sonhada, também foi defraudada pelos governos pós ditadura. A homérica neoliberal fez reforçar o totalitarismo do mercado e do consumo. Nesse modelo, as pretensões políticas de ordem democrática mostraram-se com alcance bastante limitado.

Não obstante, a política para Hannah Arendt está na liberdade de ser e agir no espaço de pluralidade entre os homens e alicerçado no respeito à propriedade humana. Nesse aspecto, a "indicação da capacidade arendtiana de indicar caminhos teóricos a partir de problemas concretos" (LAFER, 1997, p. 65) se mostra ineficiente quando as experiências de rupturas recusam a pluralidade de condições.

\section{Referências}

ARENDT, H. O que é política? Tradução de Reinaldo Guarany. Rio de Janeiro: Bertrand Brasil, 1999.

Entre o passado e o futuro. Tradução de Mauro W. Barbosa de Almeida. São Paulo: Coleção debates, 1997.

Origens do totalitarismo. São Paulo: Companhia das Letras, 1989.

Da revolução. Brasília: Editora UNB, Ática, 1988.

ARNS, D. P. E. Prefácio. In: ARNS, D. P. E. (Org.). Brasil: nunca mais. Petrópolis: Vozes, 1985.

GABEIRA, Fernando. O que é isso companheiro? Rio de Janeiro: Nova Fronteira, 1982.

GASPAR, Ronaldo. Hannah Arendt: sobre Karl Marx e a revolução. Lutas Sociais, São Paulo, n. 27, p. 58-68, 2011.

LAFER, Celso. A reconstrução dos direitos humanos: a contribuição de Hannah Arendt. Estudos Avançados, São Paulo, v. 11, n. 30, p. 55-65, 1997.

LOSURDO, Domenico. Para uma crítica da categoria de totalitarismo. Crítica Marxista, Campinas/SP, n. 17, p.51-79, 2003. 
KOSIK, Karel. Dialética do concreto. Rio de Janeiro: Paz e Terra, 1976.

MIRANDA, Mário Angelo Brandão de Oliveira. A questão da legalidade no contexto das crises políticas de 1955 a 1964 no Brasil. Dissertação de Mestrado. Pontifícia Universidade Católica (PUC). Rio de Janeiro: 2010.

NOVAES, Carlos Eduardo. Na república do jerimum. São Paulo: Nórdica, 1985.

- A história de Cândido Urbano Urubu. São Paulo: Nórdica, 1985.

Democracia à vista! São Paulo: Nórdica, 1981.

OLIVEIRA, Francisco. A dominação globalizada: estrutura e dinâmica da dominação burguesa no Brasil. In: BASUALDO, Eduardo; ARCEO, Enrique (Org.) Neoliberalismo y sectores dominantes: tendencias globales y experiencias nacionales. Buenos Aires: CLACSO, 2006. p. 265-291.

\section{Notas}

${ }^{1}$ Graduada em Filosofia pela Universidade Federal de Uberlândia (UFU). Participa do Grupo de Pesquisa Estado, Democracia e Educação - GPEDE. E-mail: anapaula248@ hotmail.com.

2 Universidade Federal de Uberlândia (UFU). Doutorando em Educação. Grupo de Pesquisa Estado, Democracia e Educação-GPEDE. E-mail: jeovandircampos@yahoo.com.br.

${ }^{3}$ Docente na UFU. Líder do Grupo de Pesquisa Estado, Democracia e Educação-GPEDE. Pesquisador CNPq e FAPEMIG. E-mail; boscodelima@gmail.com.

${ }^{4}$ De acordo com Miranda (2010, p. 171), a ideia de "Revolução", reforçada pelo editorial da Tribuna da Imprensa, jornal da época, dava entender que o golpe civil/militar se tratava de uma revolução. E ainda, "a utilização dessa ideia não se limitava a Tribuna da Imprensa, já que os líderes civis e militares da ação golpista também se auto intitulavam revolucionários".

${ }^{5}$ Hannah Arendt (1988), em Da revolução, procura desvencilhar-se dos conceitos de história de Hegel e Marx. Salienta que os autores, equivocadamente, situaram o conceito de história no "reino da necessidade" e não da liberdade como é o seu entendimento.

${ }^{6}$ Ver Domenico Losurdo (2003) e Ronaldo Gaspar (2011).

${ }^{7}$ Ah! Os filósofos que filosofam a vida... Não basta filosofar, não basta comentar a miséria... mas combatêla.

${ }^{8}$ No livro Origens do Totalitarismo de Hannah Arendt a expressão aparece como "criminosos sem crime" ao tratar dos regimes totalitários nazista e stalinista.

Recebido em Janeiro/2014

Aprovado em Fevereiro/ 2014 